\title{
"O circuito inferior no centro de São Paulo frente às dinâmicas da globalização e ao uso corporativo do território"
}

\author{
Marina Regitz Montenegro ${ }^{1}$ \\ montenegromarina@hotmail.com
}

\section{Resumo}

No texto a seguir, procuramos analisar, inicialmente, certas relações da economia popular com as variáveis-chave do período da globalização no centro da cidade de São Paulo, sobretudo no bairro da Santa Ifigênia, área de especialização (SILVEIRA, 2004) de comércio e serviços de aparelhos eletroeletrônicos. Nesta região da cidade, onde cohabitam empresas de diferentes tamanhos e níveis de capitalização, ou seja, divisões do trabalho coexistentes que compreendem circuitos da economia urbana (SANTOS, 1975), consideramos particularmente as dinâmicas atuais concernentes ao circuito inferior da economia.

Em seguida, procuramos mostrar como esta área central de São Paulo compreende justamente um dos principais focos das políticas de revitalização urbana empreendidas por sua atual administração municipal, simbolizadas pelos projetos Nova Luz e pela aprovação recente da polêmica "Concessão Urbanística". Nesta parte da cidade vem se configurando, atualmente, um cenário em que o poder público tem privilegiado abertamente as grandes empresas de tecnologia de informação e do setor imobiliário; enquanto, para os atores menos poderosos (como os pequenos negócios do circuito inferior), com menor poder de negociação junto ao Estado, têm restado, em muitos casos, a imposição do despejo e da desapropriação e a desestruturação de sua atividade econômica; ou, ainda, a repressão que confunde a pobreza e suas formas de trabalho com a criminalidade.

Daí, considerarmos que esta área do centro de São Paulo represente um espaço privilegiado da cidade para o exame das relações estabelecidas entre 0 Estado e o circuito inferior da economia no período atual. Sua análise nos permite visualizar como a conformação de um jogo de forças entre atores de níveis distintos de poderes tem permitido o avanço de um uso cada vez mais corporativo do território da cidade.

\section{Introdução}

Embora São Paulo se consolide cada vez mais como a metrópole econômica que concentra as atividades mais modernas no território brasileiro, o 
contingente de pobres e as múltiplas formas de trabalho realizadas por eles não deixam de se multiplicar na cidade. Conforme propôs Santos (1975), estas divisões do trabalho coexistentes podem ser analisadas como circuitos da economia urbana que se distinguem em função dos diversos graus de tecnologia, capital e organização assumidos pelas atividades urbanas. Quando estes são altos, trata-se do circuito superior; quando são baixos, trata-se do circuito inferior.

No período atual, São Paulo compreende, efetivamente, a metrópole onde as variáveis chave da globalização se fazem presentes de maneira mais densa no território brasileiro. Conteúdos intensivos de técnica, ciência e informação conformam as atividades mais modernas da cidade e se agregam crescentemente ao seu meio construído, ainda que de forma seletiva (SANTOS e SILVEIRA, 2001). O vigor das variáveis das finanças, do consumo e da publicidade se combina a estes elementos e permeia, de diferentes formas, a totalidade das atividades que compõem seu grande subsistema urbano, esse mercado único onde coexistem diferentes divisões do trabalho.

Cremos que a densidade da presença das variáveis chave do período da globalização em São Paulo - a técnica, a informação, o consumo, a publicidade e as finanças - implica, por sua vez, uma maior articulação do circuito inferior da economia urbana com essas variáveis na cidade (MONTENEGRO, 2006). Ou seja, seu circuito inferior, que também aparece como resultado indireto da modernização que se instala com a globalização na cidade, encontra-se relativamente mais permeado pelas variáveis-chave do período atual ao estabelecer um maior número de relações com as mesmas.

\section{O circuito inferior na globalização visto através do centro de São Paulo}

O centro histórico de São Paulo constitui um espaço privilegiado para a análise da diversidade que caracteriza o circuito inferior (SANTOS, 1975) desta metrópole, uma vez que abriga diferentes atividades de comércio, serviços e fabricação de pequena dimensão.

Antiga centralidade das atividades hegemônicas, a reflexão sobre o centro da cidade nos permite relativizar os conceitos de economia de escala e de economia de aglomeração, posto que estes variam em função das diferentes forças dos atores. As externalidades concentradas no centro representavam outrora uma verdadeira economia de aglomeração para os agentes do circuito superior. Contudo, uma vez que suas exigências de infra-estruturas modernas e de fluidez não se concretizaram nesse espaço, novas centralidades hegemônicas emergiram na cidade.

Ao mesmo passo, o centro sofreu um processo de desvalorização, desencadeado pela própria valorização desses outros pedaços da cidade. A partir daí, deram-se os dois processos que, segundo Comin (2005), passaram a definir o 
centro de São Paulo: uma "mudança no perfil de sua ocupação", com a multiplicação de atividades pouco capitalizadas, e o seu "empobrecimento". Daí a concentração crescente de atividades do circuito inferior no centro da cidade.

A região da Santa Ifigênia compreende uma área de especialização (SILVEIRA, 2004) especialmente reveladora das formas de participação, adaptação e criatividade do circuito inferior frente à modernização tecnológica característica da globalização. Referência no comércio e serviços de eletroeletrônicos, esta área abriga empresas de diferentes portes e dos mais variados níveis de capitalização. As menores empresas realizam diversas tarefas relacionadas a essa especialização, concentrando-se sobretudo no comércio de artigos de "segunda-mão" e na oferta de pequenos serviços.

Os estabelecimentos menores e menos capitalizados localizam-se nas ruas paralelas e transversais à Rua Santa Ifigênia, como as ruas Timbiras e Andradas, pois aí os valores de aluguel são mais baratos, embora ainda sejam elevados para o nível de capitalização do circuito inferior. A Rua Santa Ifigênia, por sua vez, é majoritariamente ocupada por empresas mais capitalizadas, muitas vezes instaladas em galerias nas quais predominam os comércios tipo box, e por uma série de vendedores ambulantes também especializados em eletro-eletrônicos.

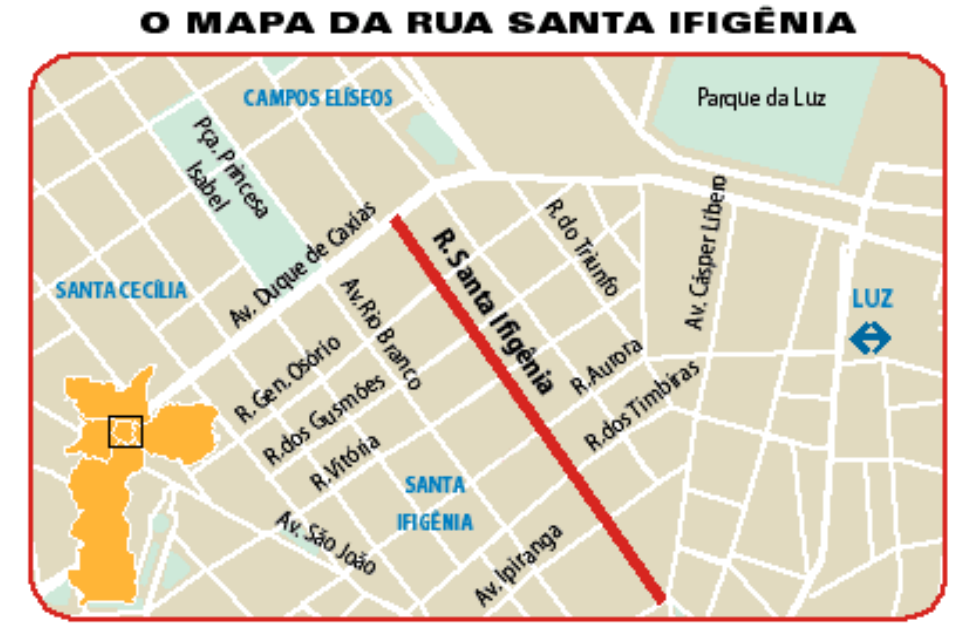

Fonte: http://www.santaifigenia.net

Os aluguéis comerciais pagos pelas pequenas empresas pouco capitalizadas na região podem alcançar altos valores, na faixa de $R \$ 1.000,00$ ou mais, ainda que os imóveis ocupados por estas sejam bastante reduzidos. Já nos espaços periféricos da cidade de São Paulo, os valores dos aluguéis pagos pelos pequenos negócios são bastante inferiores.

Assim como no restante do centro histórico da cidade, este alto valor do solo se compensa pela densidade dos fluxos, ou seja, o custo da localização é compensado pelo tamanho do mercado. Deste modo, os altos valores do solo de 
uma área de especialização como a Santa Ifigênia são contrabalançados pela enorme quantidade de pessoas que circula diariamente no centro e não chegam a impedir a presença do circuito inferior, uma vez que muitas de suas atividades continuam a ter baixos graus de capital (de giro), de organização e de tecnologia.

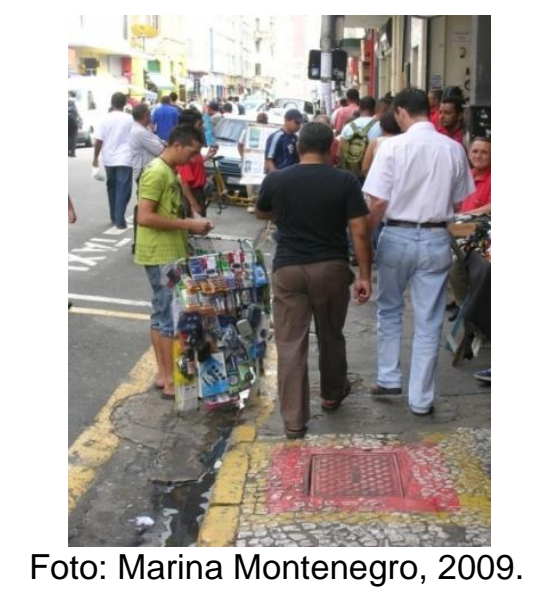

Assim, embora possamos afirmar que os pequenos negócios do circuito inferior tendam a se instalar nas parcelas mais desvalorizadas do tecido urbano, esses necessitam, todavia, de uma escala mínima de consumidores. Segundo Harvey,

(...) os valores de uso disponíveis no ambiente construído são limitados, (...) os indivíduos se utilizam do seu poder de mercado e disputam recursos escassos nas localizações mais vantajosas. Em seu nível mais elementar, essa concorrência é pelas chances de sobrevivência, pois cada trabalhador sabe que a capacidade de sobrevivência depende da capacidade de assegurar acesso a um conjunto particular de recursos numa localização razoavelmente satisfatória (HARVEY, 1982, p.31).

Dentre as atividades que compõem o circuito inferior nessa área da cidade, destacam-se, por exemplo, os pequenos comércios de artigos de "segunda mão", como telefones e controles remotos; os consertos de eletrodomésticos e de artigos de informática; recarga de cartuchos de tinha de impressora; venda de cabos e antenas de televisão; pequenos negócios de venda e troca de artigos novos e usados de informática; lanhouses etc.

A penetração das técnicas da informação no circuito inferior, ora enquanto instrumento de trabalho ora como objeto de consumo, é, assim, revelada especialmente nessa área da cidade. A criatividade oriunda do contato com as mesmas produz não apenas novos usos, mas também novas tarefas, alargando a divisão do trabalho neste circuito.

Observa-se assim, como o circuito inferior, através de pequenos comércios de artigos eletro-eletrônicos, mas também dos serviços de reparo, participa da 
difusão da base técnica da globalização. Por outro lado, constatamos que muitas vezes os pequenos estabelecimentos se especializam na oferta de serviços a aparatos representantes de uma modernização anterior, como vídeo cassetes, toca-fitas, micro-ondas, televisões mais antigas etc. Encontramos também serviços de conversão de arquivos em aparelhos de base analógica para uma base digital: vídeos em VHS são passadas para DVD, músicas gravadas em fitas $\mathrm{K} 7$ e discos vinis para CDs e DVDs etc.

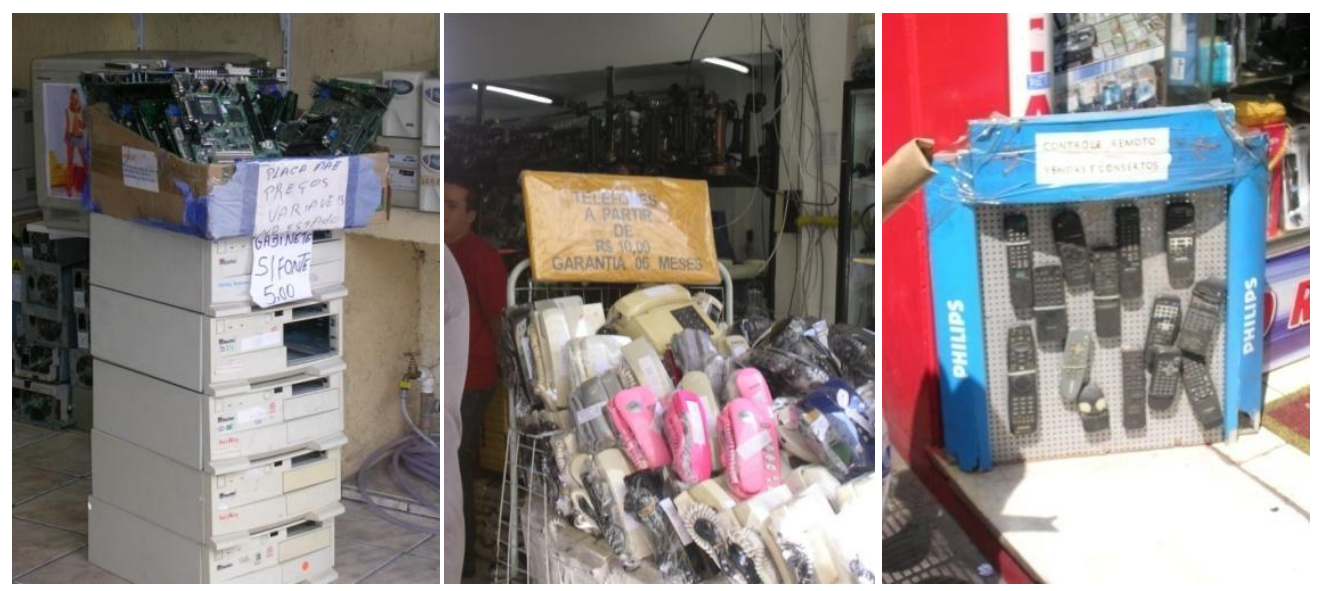

Foto: Marina Montenegro, 2009.

Através da diversificação dos equipamentos de trabalho adotados e da ampliação do leque de artigos para os quais oferecem serviços, os pequenos negócios conseguem, assim, ampliar a gama de atividades realizadas. Em algumas ocasiões, conformam-se combinações curiosas, como no caso do estabelecimento da foto acima, no qual se conserta aparelhos eletrodomésticos, alto-falantes, fornos de micro-ondas, faz-se chaves e carimbos, afia-se facas, tesouras, alicates etc.

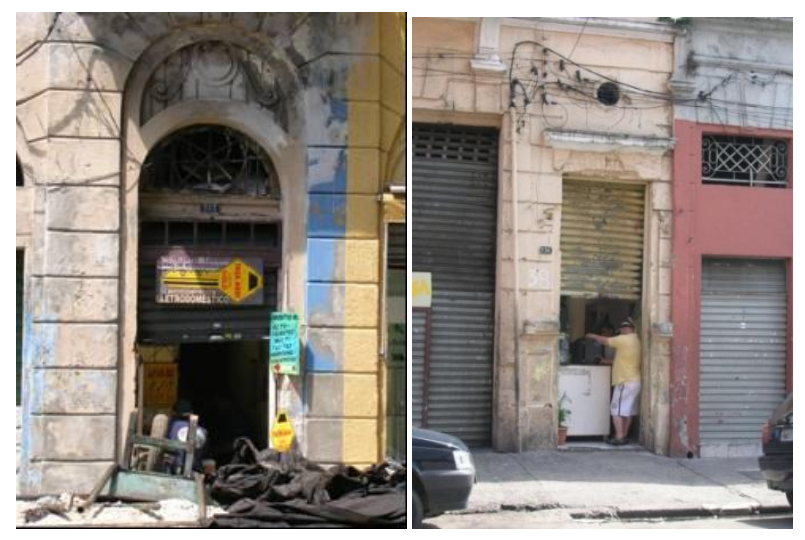

Fotos: Marina Montenegro, 2009. 
Outro dado novo que permeia o circuito inferior identificado nesta área do centro da cidade compreende a crescente participação deste circuito em circuitos espaciais de produção mais amplos (SANTOS e SILVEIRA, 2001); conforme nos revela a origem dos insumos ou artigos comercializados pelos pequenos estabelecimentos: Manaus, China e Taiwan aparecem entre as principais procedências. Daí podermos afirmar que o trabalho no circuito inferior hoje não se restringe mais, em alguns casos, aos artigos produzidos ou comprados localmente, posto que, no período atual, muitos dos insumos e das mercadorias com os quais trabalha provêm dos lugares os mais diversos, inclusive do exterior, tanto no âmbito dos serviços como no comércio. Se por um lado, tal processo envolve a participação do circuito inferior em circuitos espaciais de produção mais amplos do que no período anterior; por outro lado, implica também um estreitamento de sua articulação e dependência em relação ao circuito superior.

Ao garantir a distribuição de aparatos técnicos modernos, oriundos de grandes empresas, junto aos consumidores de baixa renda, e ao oferecer serviços de reparo a esses mesmos produtos, o circuito inferior exerce, assim, um papel ativo na difusão do sistema técnico da globalização, ou seja, participa da conformação de uma unicidade técnica (SANTOS, 1996).

Vale destacar ainda que, inclusive no ramo de eletro-eletrônicos, o circuito inferior pode também exercer a etapa da produção, através da confecção caseira de cópias de filmes e discos para comercialização. Revelam-se aí novas formas de imitação exercidas pela economia pobre, muitas vezes criminalizadas como "pirataria".

O mercado dos pequenos negócios da Santa Ifigênia abrange consumidores de diferentes níveis de renda. A financeirização das formas de pagamento, que atingiu recentemente também os pequenos estabelecimentos é intensa. A adoção dos cartões de débito e de crédito pelos pequenos negócios como forma de pagamento na cidade de São Paulo vem se dando intensamente desde 2000. O "fiado", em contrapartida, se rarefaz cada vez mais, evidenciando o avanço da financeirização das relações entre os agentes não-hegemônicos. A difusão do acesso aos cartões em meio à população de baixa renda faz parte, por sua vez, de um processo mais geral de creditização da sociedade brasileira (SANTOS e SILVEIRA, 2001) ou ainda de conformação de uma nova pobreza no país, a qual se define atualmente pela combinação paradoxal entre o aumento da pobreza e uma maior participação no consumo moderno.

Conforme procuramos mostrar brevemente, o novo no circuito inferior se estende, assim, para além da crescente inserção em circuitos globais de mercadoria. A economia pobre encontra-se igualmente permeada pelas demais variáveis-chave da globalização - a técnica, o consumo, as finanças e a informação - participando ativamente, ainda que de forma subordinada, do período atual. 
Não obstante, embora possamos afirmar que haja, de fato, um uso crescente das variáveis-chave da globalização por parte dos agentes do circuito inferior, acreditamos que este processo deva ser visto de forma contraditória. Pois se, por um lado, as situações geográficas (SILVEIRA, 1999) analisadas nos revelam diferentes formas de incorporação destas variáveis pela economia pobre, muitas vezes através de usos extremamente criativos; por outro lado, tal assimilação não deixa de representar novas formas de subordinação ao circuito superior e de se combinar tanto a diferentes estratégias de resistência a essa mesma incorporação quanto à própria impossibilidade de acompanhar o passo da modernização atual.

\section{O Programa Nova Luz e a concessão urbanística: a produção de normas e o avanço do uso corporativo do território}

Não poderíamos falar da região Santa Ifigênia sem abordar o grande projeto de revitalização para essa área da cidade, uma vez que a mesma compreende um dos principais focos das políticas de revitalização urbana da atual administração municipal de São Paulo, simbolizadas pelo projetos Nova Luz e pela aprovação recente da polêmica Concessão Urbanística. A região da Santa Ifigênia representa assim um espaço privilegiado da cidade para avaliar as relações estabelecidas entre o Estado e o circuito inferior da economia no período atual. Sua análise nos permite visualizar a conformação de um jogo de forças entre atores de níveis distintos de poderes no uso do território.

Em 2005, foi anunciado, pela Prefeitura de São Paulo, o Programa Nova Luz, cujo objetivo central consistia na "reabilitação" da área conhecida e estigmatizada como "Cracolândia", localizada no centro da cidade entre os bairros Santa Ifigênia e Luz. O projeto, financiado por parcerias público privadas, previa a renovação e a conservação de espaços públicos e privados e a transformação de mais de 2 milhões de metros quadrados a partir da definição de um Perímetro de Incentivo Fiscal e de um Perímetro de Utilidade Pública.

Segundo a Prefeitura, as diretrizes do Nova Luz consistem em um maior controle da região pela administração pública, em incentivos à produção imobiliária para o mercado, na participação de empreendedores privados no processo de renovação da área e em incentivos fiscais para atividades terciárias com ênfase na área de tecnologia da informação (EMURB, PMSP, 2009, p.9).

Para viabilizar a implementação do Nova Luz foram aprovadas sucessivamente, desde 2005, leis, decretos e resoluções que estabelecem incentivos fiscais para a instalação de empresas na região e que declaram de utilidade pública algumas áreas passiveis de desapropriação. Nesse sentido, foi feito um levantamento dos imóveis classificados como "edificações precárias, utilizadas por atividades de âmbito local que ali se estabeleceram devido aos 
baixos valores de aluguel", os quais seriam, por sua vez, "passíveis de transformação". A partir desse levantamento inicial, foram definidas as edificações a serem ou não preservadas. A seguir o mapa de uso do solo resultante dessa classificação realizada pela Prefeitura de São Paulo:

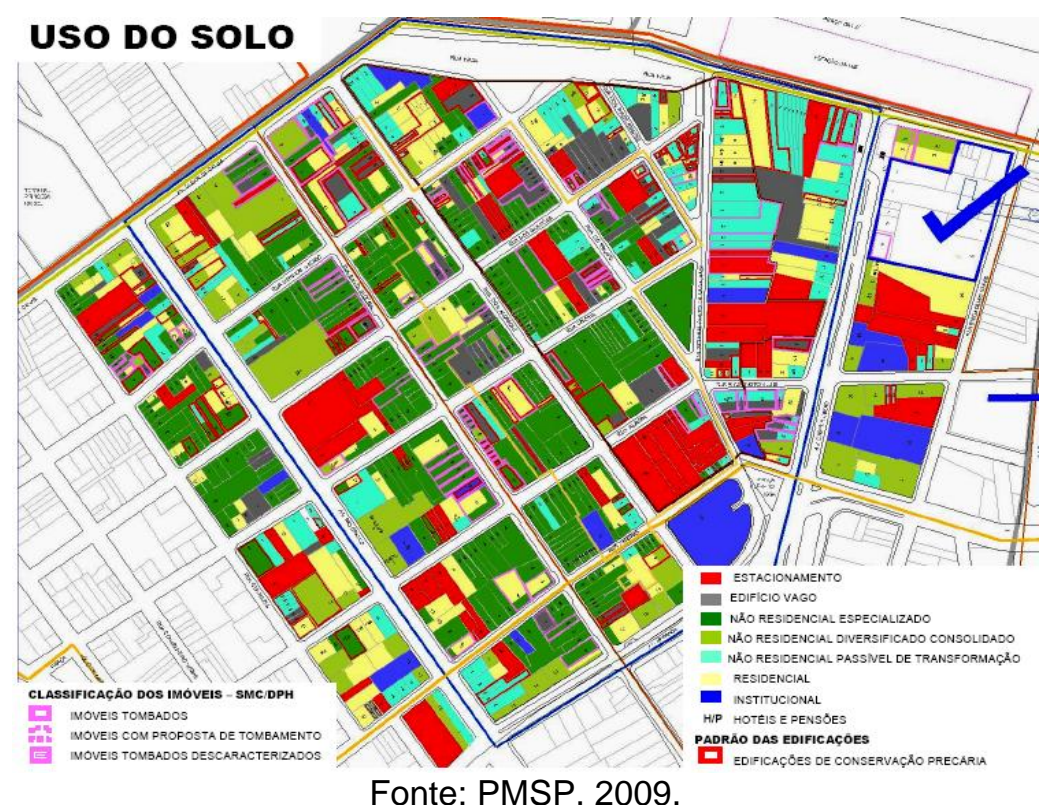

Fonte: PMSP, 2009.

Nas quadras selecionadas como piloto para o projeto, o poder público já deu início a uma série de desapropriações e demolições dos imóveis considerados inapropriados. Nessa área, também tem ocorrido fiscalizações sistemáticas, envolvendo o fechamento de pequenos estabelecimentos comerciais, apreensões de mercadorias ditas ilegais e prisões.

O Programa de Incentivos Seletivos do Nova Luz visa sobretudo a atração de grandes empresas do ramo de tecnologia da informação, o que, supostamente, estimularia a vocação econômica da região. Através da concessão de uma série de incentivos fiscais (associados ao IPTU, ITBI, ISS) e da concessão de "Certificados de Desenvolvimento", a prefeitura pretende, assim, mudar o perfil das empresas localizadas na área, almejando atrair especialmente empresas mais capitalizadas do que aquelas atualmente presentes no bairro.

Contudo, conforme buscamos demonstrar, na região da Santa Ifigênia coexistem firmas de todos os tamanhos, e são justamente as menores, instaladas em imóveis menos valorizados, que deveriam constituir a prioridade de ação do poder público, por sua capacidade de geração de trabalho e renda. Sobre esta parte da cidade, assim como sobre outras parcelas do centro de São Paulo, se pode afirmar que:

“(...) gracias a la desvalorización de los edificios, impiden una completa oligopolización de la economía y permiten la fijación de 
actividades menos capaces de dotar de valor a sus productos. Ese juego de fuerzas no es desconocido por las políticas públicas $y$ corporativas que buscan revitalizar los centros históricos" (SILVEIRA, 2007, p.160).

Embora o Nova Luz tenha sido aprovado em 2005, sua implementação efetiva ainda não ocorreu. Contudo, recentemente houve uma verdadeira aceleração nos rumos do Programa, graças à aprovação do Projeto de Concessão Urbanística em abril de 2009 para o perímetro do Nova Luz. Cremos que o desinteresse de grandes empresas incorporadoras do setor imobiliário na área tenha influenciado a aprovação do instrumento supracitado. O Programa determinava inicialmente, dentre outros, a construção de habitações de interesse social para famílias com renda de até 5 salários mínimos em $40 \%$ do perímetro do Nova Luz, o qual é definido, aliás, ao menos teoricamente, como uma Zona Especial de Interesse Social (Zeis) pelo Plano Diretor Estratégico do Município.

O instrumento jurídico da Concessão Urbanística implica a possibilidade da Prefeitura de São Paulo transferir à iniciativa privada o direito de desapropriar imóveis para a construção de novos bairros, de "revitalizar áreas degradadas" ou mesmo de construir equipamentos de interesse público. Estabelece-se, deste modo, uma complementaridade juridicamente nebulosa entre o Nova Luz e a Concessão Urbanística. Vale destacar que o projeto de lei de Concessão Urbanística em áreas consideradas "degradadas" de São Paulo e sua execução na região do Programa Nova Luz foram enviados originalmente à Câmara de São Paulo como um único projeto, tendo sido desmembrados apenas posteriormente. Não obstante, a aprovação da concessão urbanística parece anular, por um lado, as medidas previstas pelo Nova Luz relativas à população de baixa renda - que, vale destacar, concernem apenas a habitação e não a atividade econômica destes agentes realizadas no bairro - e, por outro lado, viabilizar os interesses das grandes empresas. Na prática, há certa confusão sobre o que será mantido do Programa Nova Luz original com a aprovação da concessão urbanística.

Segundo Ferreira (2009), a concessão urbanística autoriza a terceirização de áreas e até de bairros inteiros para a iniciativa privada através de uma espécie de leilão de parcelas da cidade as empresas, que ganham o direito de desapropriar terrenos na área concedida. Este instrumento jurídico permite que a iniciativa privada negocie diretamente com os proprietários dos imóveis e especule com a venda desses bens. A medida consente, assim, com que a urbanização seja cada vez mais definida pelos interesses do mercado, e não por interesses coletivos, uma vez que a Prefeitura abdica de sua prerrogativa de planejar a cidade e a repassa a grupos privados cujo interesse evidentemente não é público. Vale destacar também que a concessão urbanística já está prevista para outras partes da cidade definidas como áreas de intervenção.

Em maio de 2010, foi anunciado o consórcio de empresas que elaborará o projeto de revitalização da região em questão. A Companhia City de origem inglesa, que inclui as empresas Concremat, Aecom e FGV e foi responsável pelo 
plano diretor de Londres para as Olimpíadas de 2012, deve apresentar um projeto até o primeiro semestre de 2011. Após esse período, uma versão preliminar do projeto será divulgada e será alvo de consulta pública durante dois meses. Segundo a Secretaria de Desenvolvimento Urbano de São Paulo, tal mecanismo garantirá "a participação da sociedade civil, das pessoas que moram e trabalham na área e de especialistas" no processo... Após tal consulta, o consórcio deverá finalizar o projeto em 4 meses. Posteriormente, haverá uma nova licitação para a escolha das empresas que executarão o plano.

Vale destacar, por outro lado, que a aprovação do projeto de concessão urbanística suscitou diversas críticas e reações. Alguns questionamentos ao projeto vão no sentido deste não delinear como será realizada a desapropriação pelas empresas, ou seja, questionam a falta de detalhamento das concessões. Outros apontam que o projeto seria inviável juridicamente, uma vez que o texto não passou por uma análise das instâncias estabelecidas pelo Plano Diretor. Alega-se também que o projeto seria inconstitucional, pois o instrumento de concessão não existe para obras, apenas para serviços. Outros críticos afirmam ainda que a aprovação conjunta do projeto de concessão urbanística e do Programa Nova Luz beneficia o setor imobiliário, ao qual a atual administração municipal estaria estreitamente vinculada.

Tem se verificado também uma intensa reação por parte dos pequenos comerciantes do bairro que temem o aumento do desemprego e uma "atitude predatória" das empresas ligadas ao mercado imobiliário, segundo depoimento de lojista. A associação de comerciantes do bairro de Santa Ifigênia (ASCI) está tentando barrar o projeto na Justiça. Outras formas de resistência também têm surgido, como a retomada das ocupações de imóveis ociosos no centro por integrantes de movimentos por moradia. Na região do Nova Luz, por exemplo, há atualmente uma ocupação de um edifício na Av. Prestes Maia com mais de 1.300 pessoas...

Face às questões acima analisadas, constatamos que não há, nos projetos em questão, uma preocupação ou valorização da economia já existente na região, em especial daqueles pequenos estabelecimentos com baixos níveis de organização e capital, objeto de nossa pesquisa. Estes aparecem apenas nos itens relativos aos imóveis classificados como "passíveis de transformação" ou ainda nas "ações coordenadas" de fechamento de pequenos estabelecimentos e de apreensões de mercadorias. Entre as obras de infra-estrutura previstas, por exemplo, se privilegia a construção de tubulação para cabos de fibra óptica, importantes para firmas de gerenciamento de dados, e que serão úteis especialmente para grandes empresas. Todavia, se coloca a questão: por que não atender igualmente às demandas dos pequenos negócios?

A partir de uma classificação extremamente arbitrária do uso do solo, o Programa Nova Luz busca alterar toda a atividade econômica de uma parcela da cidade sem levar em conta a riqueza da vida de relações que singulariza esta área e os diferentes tipos de atores que aí coexistem. Através do instrumento jurídico 
da concessão urbanística, se configura, na realidade, um arranjo de forças muito desigual através do qual o poder público privilegia abertamente como parceiros as grandes empresas do setor de TI e o setor imobiliário. Já para os atores menos poderosos, com menor poder de barganha junto ao Estado, resta, em muitos casos, a imposição do despejo, da desapropriação e a desestruturação de sua atividade econômica; ou ainda, a repressão que confunde a pobreza e suas formas de trabalho com a criminalidade.

Ao invés de se pensar uma política de valorização e de potencialização da vida econômica que já existe nesta área do centro de São Paulo, avança-se explicitamente rumo ao uso cada vez mais corporativo do território da metrópole.

\section{Notas}

1 Doutoranda em Geografia Humana na Universidade de São Paulo. Bolsista da Fundação de Amparo à Pesquisa do Estado de São Paulo (FAPESP)

\section{Bibliografia}

COMIN, Álvaro. Diagnósticos, Oportunidades e Diretrizes de Ação. In: Caminhos para o Centro: Estratégias de desenvolvimento para a região central de São Paulo. EMURB, Prefeitura do Município de São Paulo, CEBRAP, CEM, p.1-30, 2005.

EMURB (Empresa Municipal de Urbanização)/ PREFEITURA DO MUNICÍPIO DE SÃO PAULO. Nova Luz. Programa de Requalificação Urbana, 2009.

FERREIRA, João Sedi W. Vende-se São Paulo. In: Correio da Cidadania (http://www.correiocidadania.com.br/content/view/3146/), 2009.

FIX, Mariana. São Paulo cidade global: fundamentos financeiros de uma miragem. São Paulo: Boitempo, 2007.

HARVEY, Dadvid. O trabalho, o capital e conflito de classes em torno do ambiente construído nas sociedades capitalistas avançadas. Tradução: Flavio Villaça. Espaço e Debates, junho/ setembro, p.6-35, 1982. MONTENEGRO, Marina Regitz. O circuito inferior da economia urbana na cidade de São Paulo no período da globalização. Dissertação (Mestrado em Geografia Humana) - Departamento de Geografia da Faculdade de Filosofia, Letras e Ciências Humanas da Universidade de São Paulo, São Paulo, 2006.

SANTOS, Milton. L'espace partagé. Les deux circuits de l'économie urbaine des pays sous-développés. Paris: M.-Th. Génin, Librairies Techniques, 1975.

Paulo: Hucitec, 1996. A natureza do espaço: Técnica e tempo. Razão e emoção. São 
SANTOS, Milton e SILVEIRA, María Laura. O Brasil: Território e sociedade no início do século XXI. Rio de Janeiro: Record, 2001.

SILVEIRA, María Laura. Uma Situação Geográfica: Do Método à Metodologia. Revista Território, n. 6, p. 21-28, 1999.

. São Paulo: os dinamismos da pobreza. In: Carlos, A. F. A. e Oliveira, A. U. de (Orgs). Geografias de São Paulo. Representação e crise da Metrópole. São Paulo: Editora Contexto, 2004. p.59-71.

. Metrópolis brasileñas: un análisis de los circuitos de la economía urbana. Revista Eure, Santiago, v. XXXIII, n.100, p.149-164, dezembro 2007. 